\section{Healing in}

\section{Sadaam's Hospital}

$\mathrm{F}$ or staff at what once was Sadaam Hussein's personal hospital, it is almost all trauma, all the time.

"In the majority of hospitals in Canada or the US, you don't see that much trauma, on average, maybe 5 or I0\%, mostly from motor vehicle accidents," says Major William White, nurse manager at the Combat Support Hospital, which the American military has occupied for the last 4 years to treat victims of the Iraq war. "It doesn't compare to what we see here. The majority of trauma cases here is 9o-to- $95 \%$ gunshots, explosions, improvised explosive devices, burns, penetrating trauma. We see about $60 \%$ of the trauma cases from the entire country."

"Over here, the primary problem is circulation," adds White. "People look for the magic on how to save lives but basically if you can stop the bleeding process you'll do wonders for the patient. We've issued tourniquets to every soldier, so kids with arms and legs blown off are surviving because they've stopped the bleeding."

Due to all the trauma cases, Major Clayton Simon, officer in charge of pathology at the Combat Support Hospital, says blood supply is critical. "We'll get 20 or 30 major casualties at one time, so we'll watch our blood bank

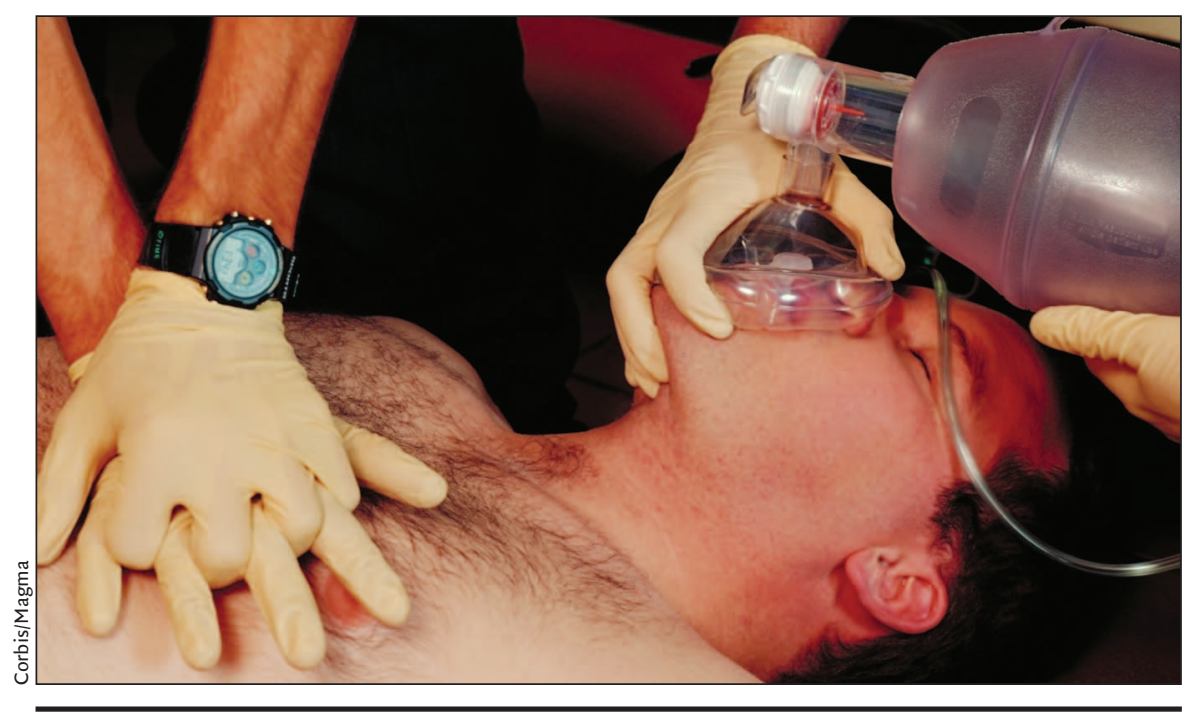

Military physicians find that service in Iraq is almost entirely about trauma. go from Ioo units to 2 units in an hour. If we get 2 or 3 of those back to back, we really start to stress the system."

It's also a challenge to work in a trauma room that does not exactly fulfill every physician's wish list. "It's a very small, meagrely equipped trauma room but it has everything we need," says White. "We do lots of thorochotomies, give large volumes of blood products, stay away from giving lots of crystalloids like sodium chloride or saline, put chest tubes in. ...We don't have oxygen pumped in like normal hospitals because when this was built in the sixties they didn't have it and we didn't want to invest the money to put it in and then in ro months or Io years turn it over to the Iraqis."

In total, the hospital has about 70 beds. About 20 non-critical patients are shipped out daily to other hospitals, with Iraqis sent to local hospitals and military personnel or foreign contractors sent to international ones.

White adds that the Iraqi health care system is improving but still having some difficulty finding adequate staff. "Iraqi physicians are now making US\$I50 to \$200 a month whereas before they were making $\$ 4$ a month because the majority of the country's money went to war efforts. But unfortunately, physicians are targeted for assassination and they're considered a good money source so they're often kidnapped, sometimes 3 or 4 times. So sometimes it's hard to fill and hard to keep those positions."
White, who is in the seventh month of his first tour of duty in Iraq, also says there is a $97 \%$ survival rate for patients who make it to the Combat Support Hospital's emergency room doors, while Specialist Rodrick Polk, who works at the hospital's blood clinic, says no one is turned away at the door. "We'll treat a suspected Iraqi insurgent just like we treat anybody else. We'll give him blood and try to save his life. Their hands and feet are usually tied and they come in blindfolded so they won't be able to see us or Iraqi workers that work here. If they did, there's a risk we could be targeted." - Jenn Gearey, Ottawa

DOI:I0.I503/cmaj.0706r5

\section{Newfoundland launches}

\section{judicial inquiry}

A provincial judicial inquiry has been struck to determine how and why hundreds of breast cancer patients received inaccurate hormone receptor tests at Newfoundland and Labrador's main medical laboratory.

Meanwhile, about roo patients and surviving family members are pursuing a class-action suit against Eastern Regional Health Authority, the agency responsible for the lab where the faulty tests were done. The patients claim false-negative results wrongly disqualified them from receiving a potentially beneficial treatment. The class-action suit was certified in the Supreme Court of Newfoundland on May 28th.

Both the inquiry and the class-action law suit stem from an estrogen-receptor testing debacle that has erupted within the province over the course of the past few weeks after it was learned that over $40 \%$ of 763 samples of breast cancer tumours taken from living patients had been erroneously identified as hormone-receptor negative.

Concerns raised by St. John's oncologist Dr. Joy McCarthy in 2005 had resulted in 939 samples collected between I997 and 2005 being sent for retesting to a lab at Toronto's Mount Sinai Hospital. The results indicated that 317 of the 763 retests done for living patients 
were false negative. Retests were undertaken for 105 of the 176 breast cancer patients who received hormone negative results since 1997 . Some 36 were found to be false negative.

A breast cancer patient's hormone receptor status helps an oncologist determine treatment options. If a patient is hormone positive she may be offered an anti-hormonal treatment such as Tamoxifen or an Aromatase Inhibitor. The drugs have risks but have been shown to increase survival rates for breast cancer patients.

Details of the debacle began emerging when Eastern Health filed documents in response to the proposed class-action suit. They indicated that the health authority hadn't publicly revealed the extent of the problem. Last December, it reported that treatment for II7 patients changed after it received all the results of the retests by Mount Sinai, but it didn't reveal that more than 300 tests were false negatives, or that at least 36 patients who received false-negative results have since died.

Opposition members in the provincial legislature pounced and after days of raucous debate, Health Minister Ross Wiseman relented and announced the judicial inquiry.

"Government recognizes it is of the utmost importance for those directly involved and the general public to understand what happened to ensure that this situation does not reoccur," said Wiseman. "Through an independent review, we will endeavour to get those answers. It is critical that patients and their families are assured that government takes this matter very seriously and that any questions they have are addressed in an open and transparent manner."

In the wake of the controversy, Premier Danny Williams also appointed a task force to examine government management of adverse events in the health system. Dates have not been set to start the judicial inquiry or the classaction suit. The commissioner's report for the judicial inquiry is expected to include recommendations about how to improve accuracy at Eastern Health's laboratory. — Mark Quinn, St. John's

DOI:I0.1503/cmaj.07074I

\section{Secret locker room game}

\section{causing concussions}

$\mathrm{T}$ here's a dangerous new game being played out in the locker rooms of hockey rinks and arenas across North America. Although most coaches, parents and certainly most doctors have never heard of "Helmets and Gloves" (also called locker boxing and buckets), they are quickly becoming more familiar with the cuts, bruises and concussions that are ensuing from the game.

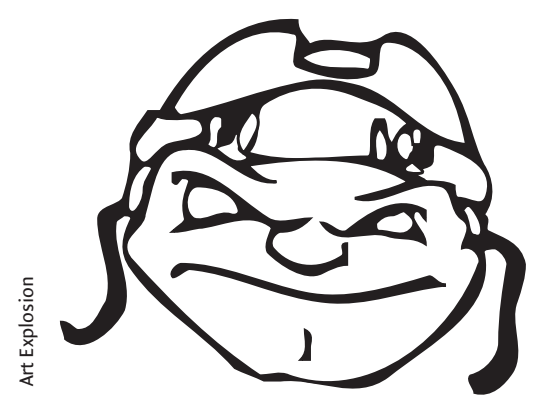

Locker room goonery takes toll on youngsters.

Dalhousie University Associate Professor of Pediatrics Dr. Kevin Gordon learned of the game and consequences while treating injured athletes at the IWK (Izaak Walton Killam) Health Centre in Halifax.

A bit of Internet investigation soon led Gordon to videos of matches posted on YouTube and other sites popular with young people. The game, seen as a test of "manhood," has few rules and even less equipment. Participants, wearing only gloves and helmets, knock one another about the head until someone falls to the ground or a helmet flies off. While shoulder dislocation, cuts from skate blades, and even toe amputation are among reported injuries, the primary concern is concussion.

In particular, "it's the concussion upon the concussion that is the big worry," Gordon notes. "If you play while concussed, you are more likely to get concussed again. You get a cumulative effect."

In regulated sports, a team member would not be able to play for a specified period of time after suffering a concus- sion. "[But] these are concussions that aren't even going on anyone's radar," says Gordon, who now includes questions about Helmets and Gloves on every concussion history he takes.

In many cases, kids do not even consider the blackout they suffer or the head injury they receive as a result of the locker room game to be an actual concussion because it was never diagnosed as such, Gordon says. Donalee Moulton, Halifax

DOI:Io.I503/cmaj.070742

\section{News@ a glance}

User fee minuet: Claude Castonguay, former provincial Liberal cabinet minister, so-called father of Quebec medicare and recent advocate of user fees, has been appointed by Quebec's minority government to head a 3 person task force to examine the "sustainability" of the province's health-care system. Quebec Finance Minister Monique Jérôme-Forget mandated the task force to examine all manner of options, including the expansion of private clinics and the introduction of federally-prohibited user fees as a potential new source of revenue for the health system. Imposing user fees would require amendments to the Canada Health Act, but Jérôme-Forget argued that the provinces may need such flexibility if they are to absorb spiraling health care costs. The task force is also mandated to "define the role the private sector can play to improve access and reduce wait times."

Training flap: British Medical Association Chair James Johnson resigned last month after 4 years at the helm when tempers flared over a letter he wrote to a newspaper defending the controversial Medical Training Application Service, which is used to match junior doctors to specialist posts. Trainee doctors argue the appointment system, under which over 34000 graduates are chasing 18500 training posts, is flawed and unfair because of poorly designed forms, technical failures with online applications and the shortage of avail- 